\title{
Visual capture of haptically judged depth
}

Using a graduated scale, $S$ was required to match with his left hand the depth of three objects of equal physical depth (or thickness) held with the right hand. While making these haptic depth judgments the objects were viewed. Due to its optical properties, one object was of greater apparent visual depth than the other two, which served as controls. The critical object was judged to be of greater haptic depth than the control objects, thus demonstrating visual capture of haptic depth. This outcome is similar to that noted previously for haptically judged direction, size, and orientation with transformed visual input.

Recent studies have shown that when visual and tactile-proprioceptive (or "haptic") cues for the spatial properties of an object are in conflict, judgments are made mainly in terms of visual cues. This dominance of vision over the haptic sense, sometimes called "visual capture" (Tastevin, 1937; Hay, Pick, \& Ikeda, 1965), is usually demonstrated by modifying the spatial characteristics of visual input by interposing an optical device (prism, lens, mirror) between object and eye. Visual capture has now been shown for direction (Harris, 1963, 1965; Hay, Pick, \& Ikeda, 1965), size (Rock, 1965; Rock \& Victor, 1964; Rock \& Harris, 1967), and orientation (Over, 1967; Singer \& Day, 1966). Taken together, these data convincingly show that visual space is primary and that, contrary to the classical view of Berkeley, vision educates "touch" (where touch is taken to mean the haptic sense).

It is of interest to note that, while visual dominance has been demonstrated for direction, size, and orientation, it has not been shown for depth or solidity. The recent availability of objects with apparent depth considerably greater than true depth has made it possible to investigate this fundamental problem, first raised by Berkeley in his "An Essay Towards a New Theory of Vision" in 1709. An experiment is reported here which shows that when visual cues conflict with haptic cues for depth, the former are dominant and strongly influence haptic depth judgments.

\section{Apparatus}

\section{METHOD}

The apparatus shown in Fig. 1 was designed to allow $S$ to match the depth or thickness of a stimulus object held between thumb and index finger of the right hand, using a tapering wedge held between the same fingers of the left hand. The main component was a metal box $17.75 \times 12 \times 6.25$ in., open on its left side relative to $S$. Attached to the right side $14 \mathrm{in}$. from the base was a $5.75 \times 4.375$-in. frame into which could be placed the Plexiglas-covered stimulus objects. The center of the stimulus object in the frame was at approximate eye-height for a seated $\mathrm{S}$. The true thickness of the stimulus object was concealed by a box-like cover attached to the back of the frame. At a distance of $2.75 \mathrm{in}$. from the open side of the box attached to the base and facing the opening, was the 17.375-in. elongated wedge, $1.25 \mathrm{in}$. wide at its base and tapering to $.0615 \mathrm{in}$. at its apex (Fig. 1). This wedge was out of view, but could be easily reached and grasped by S. A scale was marked on the wedge so that the position of S's thumb and index finger could be easily read.

\section{Stimulus Objects}

The first object (A) was a stereo-pair constructed according

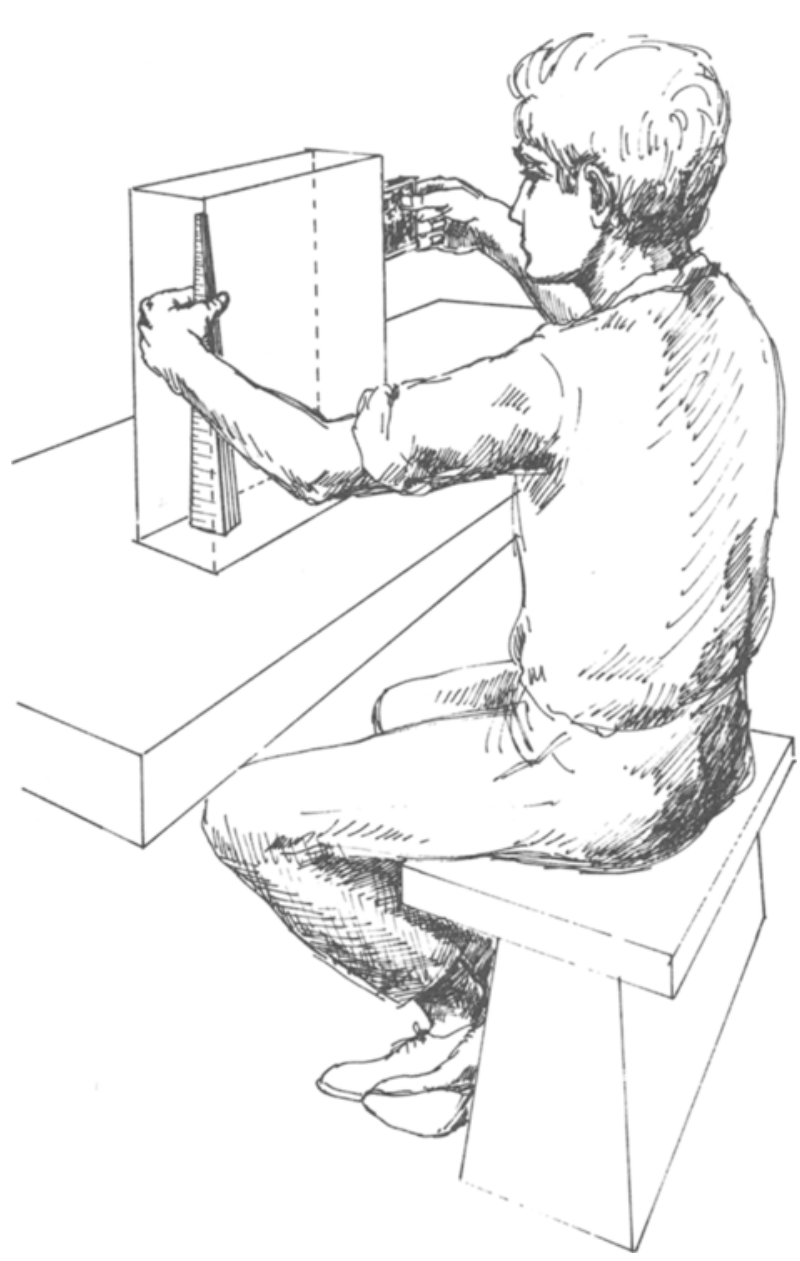

Fig. 1. Apparatus used for matching with the left hand the apparent depth of the object held with the right hand.

to a principle described by Longhurst (1957). In front of two specially prepared "cartoon" pictures was placed a lenticular grid whose linear elements were actually long and very narrow cylindrical lenses. Refraction by these elongated elements caused each eye to view one of the two slightly disparate pictures. The picture was a "cartoon-scene" of animals in a wood and, although .135 in. deep, it conveyed a compelling impression of depth. The second object (B) was a colored photograph of $\mathrm{A}$, and while color and form were faithfully reproduced, there was no apparent three-dimensional effect as in A. The third object (C) consisted of a plain buff-colored card. Since the three stimulus cards were mounted between Plexiglas, the tactile stimulus was the same throughout. In summary, A was constructed so that its apparent depth was substantially greater than its true depth, B was similar to A but without the three-dimensional effect from disparity, and $C$ was plain. Thus, Objects B and C served as controls for $A$ in investigating the effects of visual cues on haptic depth judgments. 


\section{Subjects}

There were three groups of nine male and female Ss, all of whom were members of an introductory class in psychology. None was familiar with the problem.

\section{Procedure}

The blindfolded $S$ was conducted into the laboratory and seated before the apparatus. Two practice trials were given in which S, still blindfolded, was required to match the depth of the object held between thumb and index finger of the right hand with a position on the scale held between the same fingers of the left hand. The main purpose of the practice trials was to emphasize to $S$ that the haptic depth of the object was to be judged.

Following the practice trials the blindfold was removed and $S$ underwent four trials in which he matched the haptic depth of the object in the same manner while simultaneously viewing it. For two of the trials S's left hand was placed by $E$ at the top of the graduated scale, and for the other two at the bottom, the starting position alternating from trial to trial. When $\mathbf{S}$ indicated that he was satisfied with the match the position of his thumb and index finger on the graduated wedge was read and recorded.

The first group viewed and judged Object $\mathrm{A}$, the second group, B, and the third group, C.

\section{RESULTS}

The score was the mean of the four haptic depth matches made with the left hand on the graduated scale. The group means were .39 in. for $\mathrm{A}, .23$ for $\mathrm{B}$, and .28 for $\mathrm{C}$. An analysis of variance was carried out on the data. Using the mean square variance within (MSW) Rodger's (1965) planned contrasts showed that the mean apparent depth for the group judging $\mathrm{A}$ differed significantly from that judging $B$, but that the means for the groups judging $B$ and $C$ were not significantly different $(\mathrm{MSW}=0.011, \mathrm{df}=2 / 24)$. The Type 1 error rate was set at .01 .

\section{DISCUSSION}

It has been shown previously that when visual direction, size or orientation are modified by interposing an optical system between object and eye, haptic judgments are made largely in terms of the modified visual input. In the present experiment visual input was modified by introducing a disparity between the images to right and left eyes, thus causing a visual appearance of depth. The data reported here show that visual capture of haptically judged space occurs also in respect of object depth or solidity.

While this result could reasonably have been predicted from earlier findings reviewed in the introduction, it does partly answer a question of long standing. Berkeley in his "An Essay Towards a New Theory of Vision" was concerned inter alia with the origins of visual depth and distance, i.e., with the origins in perception of the visual third dimension. His conclusion, which was for long accepted, was that visual depth derived from touch (by which he meant mainly the haptic sense) by association. The data reported here show that in the adult, visual depth largely determines haptic depth. Whether this dominance of visual over haptic cues occurs during the course of development is yet to be established.

\section{REFERENCES}

DAY, R. H., \& SINGER, G. Sensory adaptation and behavioral compensation with spatially transformed vision and hearing. Psychological Bulletin, 1967, 67, 307-322.

HAY, J. C., PICK, H. L., \& IKEDA, K. Visual capture produced by prism spectacles. Psychonomic Science, 1965, 2, 215-216.

HARRIS, C. S. Adaptation to displaced vision: Visual, motor, or proprioceptive change. Science, 1963, 140, 812-813.

HARRIS, C. S. Perceptual adaptation to inverted, reversed, and displaced vision. Psy chological Review, 1965, 72, 419-444.

LONGHURST, R. S. Geometrical and physical optics. London: Longmans, Green and Co., 1957.

OVER, R. An experimentally induced conflict between vision and proprioception. British Journal of Psychology, 1966, 57, 335-341.

ROCK, I. Adaptation to a minified image. Psychonomic Science, 1965, 2, 105-106.

ROCK, I., \& HARRIS, C. S. Vision and touch. Scientific American, $1967,216,96-104$.

ROCK, I., \& VICTOR, J. Vision and touch: An experimentally created conflict between the two senses. Science, 1964, 143, 594-596.

RODGER, R. S. Intermediate statistics. Sydney: University Co-operative Bookshop, 1965.

TASTEVIN, J. En partant de l'experience d'Aristotle. L'Encephale, $1937,1,57-84,140-158$.

\section{NOTE}

1. Address: Department of Psychology, Monash University, Clayton, Victoria 3168, Australia.

(Accepted for publication Jenuary 6, 1969.) 